\title{
Behavioural design: A process for integrating behaviour change and design
}

\author{
Cash, Philip; Hartlev, Charlotte Gram; Durazo, Christine Boysen
}

Published in:

Design Studies

Link to article, DOI:

10.1016/j.destud.2016.10.001

Publication date:

2017

Document Version

Peer reviewed version

Link back to DTU Orbit

Citation (APA):

Cash, P., Hartlev, C. G., \& Durazo, C. B. (2017). Behavioural design: A process for integrating behaviour change and design. Design Studies, 48, 96-128. https://doi.org/10.1016/j.destud.2016.10.001

\section{General rights}

Copyright and moral rights for the publications made accessible in the public portal are retained by the authors and/or other copyright owners and it is a condition of accessing publications that users recognise and abide by the legal requirements associated with these rights.

- Users may download and print one copy of any publication from the public portal for the purpose of private study or research.

- You may not further distribute the material or use it for any profit-making activity or commercial gain

- You may freely distribute the URL identifying the publication in the public portal 


\title{
Behavioural Design: A Process for Integrating Behaviour Change and Design
}

Design Studies

Philip J. Cash ${ }^{* 1}$, Charlotte Gram Hartlev ${ }^{1}$, Christine Boysen Durazo ${ }^{1,2}$

Please cite this article as: Cash, P., Gram Hartlev, C., \& Durazo, C. B. (2017). Behavioural Design: A Process for Integrating Behaviour Change and Design. Design Studies, 48(January), $96-128$.

\section{Highlights}

$>$ A case study surveying 20 behavioural design projects is reported.

$>$ Significant patterns in process progression are found in the surveyed projects.

$>$ A new design process is proposed that integrates behaviour change and design.

$>$ Key learnings for behaviour change through design are identified.

\begin{abstract}
Nudge, persuasion, and the influencing of human behaviour through design are increasingly important topics in design research and in the wider public consciousness. However, current theoretical approaches to behaviour change have yet to be operationalized this in design process support. Specifically, there are few empirically grounded processes supporting designers in realising behaviour change projects. In response to this, 20 design projects from a case company are analysed in order to distil a core process for behavioural design. Results show a number of process stages and activities associated with project success, pointing to a new perspective on the traditional design process, and allowing designers to integrate key insights from behaviour change theory. Using this foundation we propose the Behavioural Design process.
\end{abstract}

Keywords: user behaviour; behavioural design; design method; product development; case study 
Technology optimisation and removal of choice have long been the basis for technical approaches to changing user behaviour e.g. a heating system that turns off automatically (Greening, Greene, \& Difiglio, 2000; Herring \& Roy, 2007; Horvath, 2004). However, technical approaches alone are insufficient for sustaining behaviour change, as highlighted by e.g. Lilley (2009). Thus there is a drive to influence users' behaviour through interventions designed into the product e.g. a heating system that provides feedback on energy consumption (Jackson, 2005; Tang \& Bhamra, 2008). This is illustrated by the rise of persuasive design (Fogg, 2009a) and the resurgence of unconscious behaviour change research e.g. nudging, in psychology (Kim, Yoon, \& Gonzalez, 2012; Thaler \& Sunstein, 2008).

Behaviour change theory has been operationalized in a number of specific design process and method propositions. These reflect a spectrum of behavioural strategies; from fully conscious to fully unconscious or combinatory. In this context, strategy describes the overall approach to behaviour change, including deployment, intervention, monitoring, and data gathering (Fogg, 2009a; Kelders, Kok, Ossebaard, \& Van Gemert-Pijnen, 2012). Bringing these areas together, we offer an initial characterisation of Behavioural Design as: designing for antecedent behaviour change strategies using implicit interventions to impact behaviour. This is complementary to, but distinct from, the range of approaches described by persuasive design or technology (Kelders et al., 2012), and physical removal of choice (Herring \& Roy, 2007).

Examining the current state of the art in both design for sustainable behaviour (Bhamra, Lilley, \& Tang, 2011; Selvefors, Pedersen, \& Rahe, 2011) and persuasive design (Kelders et al., 2012) highlights three key challenges. First, there is little explicit research on, or process support for, the implementation of unconscious strategies. Of the possible unconscious strategies listed Dolan et al. (2014) (e.g. priming and ego), only one is explicitly identified by Selvefors et al. (2011). Second, there is little empirical data on the effectiveness of proposed process support in this domain (Bhamra et al., 2011; Kelders et al., 2012). Third, most current design processes focus on realising technologically facilitated behaviour change i.e. technology is used to actively drive the interaction between the user and the behavioural intervention (Kelders et al., 2012). This is in contrast to many unconscious strategies that can also be realised through implicit interventions (DeMarree, Wheeler, \& Petty, 2005; Michie, Johnston, Francis, Hardeman, \& Eccles, 2008; Tromp, Hekkert, \& Verbeek, 2011).

Based on these challenges there is a need for a new process perspective, delivering empirically grounded support to teams designing for unconscious behaviour change. This need is emphasised by both Visser et al. (2011) and Nurkka et al. (2009) in their discussions of design for social connectedness and user value perception. Further, the need for support in this 
domain is particularly significant because of the complexity and variety of unconscious strategies available to the designer (Abrahamsen, Steg, Vlek, \& Rothengatter, 2005; De Young, 1993). As such, the goal of this work is to distil a behavioural design process empirically linking process framing, stages, and activities, to successful process outcomes.

As with all design process models the first step in defining Behavioural Design is identifying its core stages and activities (Blessing, 1994; Wynn \& Clarkson, 2005). Thus Section 1 examines theory on behaviour change processes as well as current operationalization efforts in the design domain. Sections 2 and 3 then deal with the empirical study. Subsequently, the behavioural design process is synthesised from both the review and the empirical findings in Section 4. Finally, a number of implications for both design research and design practitioners are distilled in Section 5.

\section{Background}

In order to synthesise a robust behavioural design process it is necessary to consider both theoretical (Section 1.1) and operational (Section 1.2) aspects of design for behaviour change.

\subsection{Behaviour Change Strategies}

Behaviour can be described in terms of: antecedent (trigger) > behaviour > consequence (result) (Miltenberger, 2011). This interpretation has been elaborated in other fields by Michie et al. (2008) and Hardeman et al. (2005), amongst others, and is recognised in design by authors such as Lehman \& Geller (2004) and Wood \& Newborough (2003). Antecedent strategies use interventions that occur prior to a behaviour, influencing it in a desired direction (Abrahamsen et al., 2005). Consequence strategies use interventions that occur during or after a behaviour has been performed (Abrahamsen et al., 2005) e.g. using rewards, fees, and feedback. Critically, consequence strategies primarily rely on the subject reflecting on their actions.

Strategies can be further decomposed into: informational, and structural. Informational strategies include most current design and persuasive approaches (e.g. priming, role models, and social support)(Kelders et al., 2012). Structural strategies "are aimed at changing contextual factors such as the availability and the actual costs and benefits of behavioural alternatives" (Steg \& Vlek, 2009, p. 313). These prevent behaviour by e.g. limiting access to products that facilitate that behaviour. Finally, strategies can exert influence in a number of ways from coercion to seduction (Tromp et al., 2011). Although, coercion and the removal of freedom of choice can be effective it is often associated with negative consequences, such as, 
poor user experience or subversion of the intended behaviour (De Young, 1993). As such, this work focuses on strategies that retain freedom of choice.

Design interventions can target: conscious and unconscious systems of thought, based on Dual Process Theory (Kahneman, 2011). Unconscious interventions target System 1 thinking, which builds on associative reactions to situations and uses intuitive and automatic processes. Conscious interventions target System 2 thinking, which builds on reflection and explicit reasoning processes. Although both have been demonstrated as effective (Dwyer \& Leeming, 1993; Lehman \& Geller, 2004), unconscious processes lend themselves particularly to passive or implicit interventions e.g. environmental stimuli or priming (Bargh \& Chartrand, 2000). This is in contrast to active interventions (Kelders et al., 2012). Further, the design literature has typically focused on the operationalization of active interventions (Kelders et al., 2012), with little work dealing with the operationalization of implicit interventions (Lehman \& Geller, 2004; Tromp, 2013; Wood \& Newborough, 2003). This is despite their demonstrated applicability in antecedent informational strategies (Michie et al., 2008). Thus, this work brings together antecedent information strategies and implicit interventions in an operationalized design process (Tromp, 2013). This explicitly differentiates behavioural design from prior approaches (Bhamra, Lilley, \& Tang, 2008; Kelders et al., 2012).

In the context specified above, De Young (1993) breaks down general informational strategies into: purely informational, and positive motivational. Purely informational emphasise awareness of a problem, and how future behaviour will affect this. Positive motivational encourage people to perform specific actions. Both types emphasise freedom of choice. Key to implicit interventions is that both informational and positive motivational can be realised through physical cues e.g. pictures, objects or written material (Kim et al., 2012; Schultz, Oskamp, \& Mainieri, 1995). Cues change the environment and context of a behaviour, as well as providing a trigger for change (Schacter, 1992). Cues can be delivered in a number of ways and can target conscious or unconscious decision making (Ouellette \& Wood, 1998; Steg \& Vlek, 2009).

These different considerations are summarised in Figure 1. This illustrates the different routs available when designing for behaviour change. Each rout highlights a different strategy coupled with a different behavioural (antecedent - consequence) and cognitive target (conscious - unconscious). These can be further modified by the means of exerting influence and the type of artefact used. As such, design for behaviour change presents a multidimensional problem with a number of interacting elements, which are also culture and context dependant. 


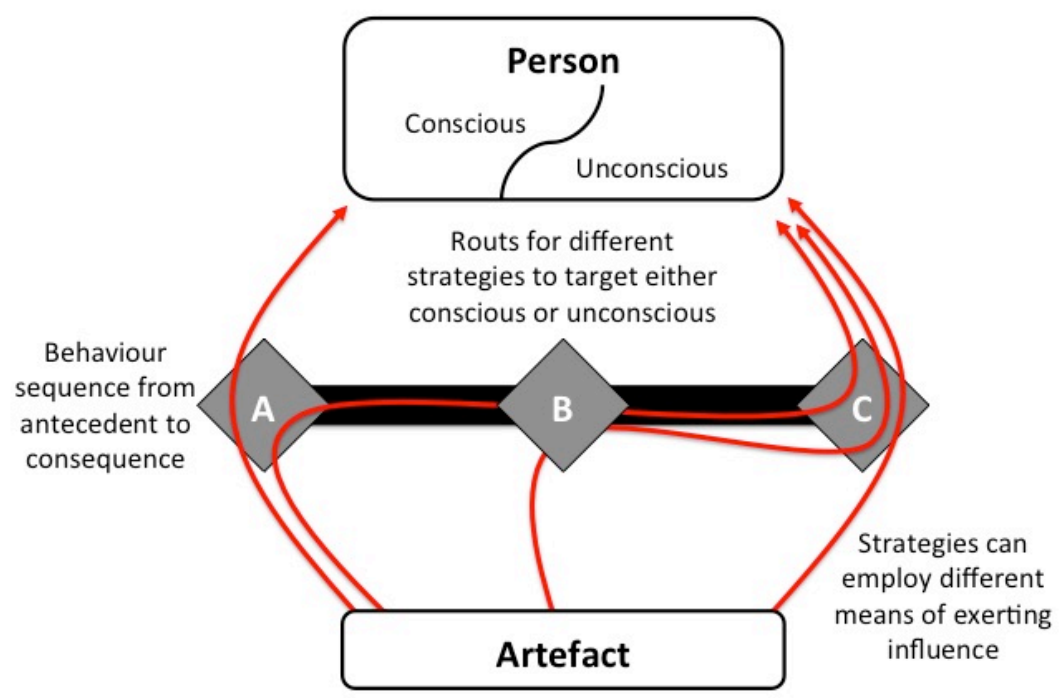

Figure 1: Elements to consider in design for behaviour change

Implicit cues can be delivered via a wide range of artefacts and link to a number of psychological constructs. For example, priming is widely used in this domain (Kay, Wheeler, Bargh, \& Ross, 2004). Priming is an effect where exposure to a stimulus influences the automatic response to subsequent stimuli (Schacter, 1992). This effect is explained via Implicit Memory where prior experiences influence subsequent behaviour without conscious awareness (Roediger, 1990). However, the effects of priming are also highly susceptible to an individual's sense self in the social context (S. E. Cross \& Madson, 1997; Evans, 2008) or selfconstrual i.e. "the relationship between the self and others and, especially, the degree to which [people] see themselves as separate from others or as connected with others" (Markus \& Kitayama, 1991, p. 226). Self-construal affects the way people relate to others and how they see themselves with respect to the social context (Stapel \& Koomen, 2001). Thus, selfconstrual mediates behaviours people associate with social interactions e.g. positive perception of pro-social actions (Zhang, Feick, \& Price, 2006). Further, self-construal is linked to perceived social norms, which effect how people behave in a given situation (Cialdini, 2007). Here, it is not necessarily what others do, but what people think they do, that has an effect on a person's behaviour (Cialdini, 2007; Lockton, Harrison, \& Stanton, 2008; Schultz et al., 1995). Thus the impact of priming delivered through environmental cues is mediated by an individual's perception of self and social norms.

Two key conclusions can be drawn from the priming example above. First, even relatively welldescribed strategies have a complex mix of factors that influence their realisation in practice. Second, due to this complexity any behavioural design process must be robust across a range of strategies, intervention types, and contexts if it is to be effective. These conclusions are illustrated by the increasing focus on these effects in the psychology and social policy domains 
(Marteau, Ogilvie, Roland, Suhrcke, \& Kelly, 2011) contrasted with the lack of uptake in the design domain. Reviewing the core design journals for terms associated with unconscious behaviour change e.g. nudge and priming (Design Studies, Journal of Engineering Design, and International Journal of Design; range: 2000-2014, abstract, title, keywords) only one article deals with nudging in the context of behaviour change (Visser et al., 2011). Further, no articles were found to deal with integrating unconscious behaviour change principals into specific design processes. This highlights the fact that this topic is still little represented or supported in the core design literature. As such, the next section examines what methods and other operationalization efforts have been proposed and what key features can be distilled from these.

\subsection{Operationalization of Behaviour Change Strategies in Design}

Active conscious strategies are broadly operationalized in persuasive design (Fogg, 2009a; Lilley, 2009). For example, Fogg (2009a) focuses on behaviours were a technology is used as the platform for launching the intervention. Persuasive technologies typically support motivation or ability, as well as providing an active trigger for behaviour. Of all the approaches described in the systematic review of Kelders et al. (2012) only similarity (the artefact is designed to look familiar) and liking (the artefact is designed to be attractive) focus on implicit elements. Further, neither of these are directly concerned with driving a behavioural affect, rather they facilitate other active strategies. This is in contrast to e.g. priming, which can be both implicit and still have a behavioural affect (Dolan et al., 2014). As such, it is important to look beyond the persuasive design literature when considering unconscious strategies.

Focusing on the unconscious Thaler and Sunstein (2008) define nudge as: "any aspect of the choice architecture that alters people's behaviour in a predictable way without forbidding any options or significantly changing their economic incentives" (p. 6). This uses subtle environmental cues to influence automatic behaviours. An example of where this has been used is in priming which works on basic associations (Bargh \& Chartrand, 2000) e.g. negative or positive valence (Williams \& Bargh, 2008), and the creation of stereotypes (Cox, Abramson, Devine, \& Hollon, 2012). These can influence feelings, decisions, and behaviours that are subconsciously processed and automatically created (Bargh \& Chartrand, 2000), resulting in a powerful vector for behaviour change. This is linked to real world impact along with other behaviour change strategies by Tromp \& Hekkert's (2016) design for social responsibility (Tromp et al., 2011). 
In the psychology domain researchers have focused on understanding behaviour, and thus offering theoretical guidance for strategies and interventions in practice. For example, Prochaska et al.'s (1997) Transtheoretical model describes an individual's decision-making process in terms of six stages, from pre-contemplation to action and maintenance. Based on this, Prochaska et al. (1995) propose nine approaches to support change at a population level. However, these recommendations do not describe process stages or activities associated with realising these changes through design. Similarly, Hardeman et al.'s (2002) systematic review of interventions derived from the Theory of Planned Behaviour highlight a number of recommendations (e.g. persuasive communication, experience of successfully completing the behaviour, observing others successfully completing the behaviour, and physiological feedback) but do not deal with how these might be achieved in a design context. The same issue is highlighted Godin et al. (2008) with respect to Social Cognitive Theory. Bringing together operationalization efforts in the psychology domain Francis et al. (2009) systematically reviewed: Knowledge-Attitude-Behaviour model, Theory of Planned Behaviour, Social Cognitive Theory, Operant Learning Theory, Control Theory, Normative Model of Work Team Effectiveness, and Action planning approaches. Francis et al. (2009) conclude that although these models provide insight into behaviour change there are few theories that deal with the practical design stages and activities involved.

In the design domain models have addressed the process perspective by focusing on behaviours linked to technical artefacts. However, these have typically focused on active conscious strategies as highlighted in the opening of this section (Fogg \& Hreha, 2010; Lilley, 2009; Lockton, 2016). Further, these models articulate frameworks more akin to mindset or framing tools rather than operational process stages and activities. Similarly, Socially Responsible Design (Tromp et al., 2011; Tromp, 2013) and the Stage-Based model (Li, Dey, \& Forlizzi, 2010) offer guidance in framing behavioural design projects, contextualising the design effort, and establishing behaviour-focused mindset. However, they offer little direction on the process stages to be followed. In terms of stages and activities both Selvefors et al. (2011) and Wendel (2013) offer generic characterisations of design processes targeting behaviour change. Wendel in particular delivers a rich characterisation of design for behaviour change and its associated issues. However, these processes each offer a number of unique suggestions, with little empirically supported guidance as to how these should resolved.

At the more practical level tools such as MINDSPACE (Dolan et al., 2014) and the Behaviour Change Wheel (Michie et al., 2008) provide frameworks related to specific activities. In contrast to the models outlined above, these approaches lack integration between the 
activities they support and the wider process. This reduces their utility in product design teams not already having a behaviour-focused mindset.

Thus although prior operationalization efforts link back to core psychological theories e.g. Dual Process Theory (Kahneman, 2011) or Implicit Memory (Schacter, 1992), they provide incomplete support in the design domain. In particular, there are a range of possible process stages and activities described, related to a variety of mostly conscious strategies. As such, the question remains: which stages and activities are associated with successful behavioural design projects? Further, there is a need to link framing and mindset perspectives to specific behavioural design activities in a core process.

\subsection{Research Framework}

Bringing together the review there is need for design support at a number of levels, from overall process to specific tools. However, as highlighted by Ulrich and Eppinger (2003) specific methods and tools are less effective when not integrated in a cohesive process. Thus given the lack of extant research in this area, characterisation of stage and activity progression is an essential prerequisite for further investigation of more specific sub-tasks e.g. supporting creativity. As such, this work aims to distil these stages and activities in a structured way in order to empirically link process progression and process outcome.

In order to acknowledge the range of strategies available to the designer, and the distinction from prior works on design for behaviour change, we refer to our focus area as Behavioural Design. This is defined as: designing for antecedent behaviour change strategies using implicit interventions to impact behaviour. The main advantage of behavioural design is that implicitly incorporating the intervention into an artefact reduces the likelihood of conscious recognition, and thus awareness that can negate the intended effect. This is in contrast to e.g. persuasive design's general focus on active, technologically facilitated strategies where users are presented an intervention, which can drive counteraction. Behavioural design targets automatic response, eliminating possible counteraction through implicit effect whilst retaining freedom of choice.

In order to characterise an empirically supported behavioural design process at the stage and activity level it is necessary to address the following research aim, and sub objectives:

Aim: Distil a behavioural design process empirically linking process framing, stages, and activities, to successful process outcomes.

Objective 1: Distil a core process associated with behavioural design from the myriad possible stages and activities described in current literature. 
Objective 2: Evaluate this process with respect to its effectiveness in realising a successful outcome for the involved stakeholders.

Objective 3: Evaluate this process with respect to its robustness across intervention types and other dimensions of design work likely to be encountered e.g. team size.

\section{$2 \quad$ Method}

In order to answer the aim and objectives outlined in Section 1.3 it is necessary to evaluate a wide range of process examples in a common context. Thus a case study approach was adopted supported by Qualitative Comparative Analysis (QCA).

\subsection{Case Context}

The selected company is the largest of only two companies in Denmark, and one of very few in Europe that specifically focus on projects incorporating behavioural design. The company is an SME dealing with both private and public sector projects with a wide range of design briefs. The company was selected because their projects include influence through physical products, software, advertising campaigns, systems design, and choice architecture. This gave a wide range of project scopes and foci around the common theme of behavioural design (Obj. 2). Further, this gave a foundation for distilling more general process dynamics robust across a range of design contexts (Obj. 3). Together this allowed for evaluation and synthesis of a wide range of process stages and activities (Obj. 1). The stages and activities observed in the company are differentiated with respect to the work of Wynn \& Clarkson (2005) i.e. stages describe strict progression while activities within stages are iterative.

Further, the core team of designers (10 people) have been involved with every project in the company's portfolio, providing excellent data access. This allowed for a consistent assessment of projects and supported triangulation. In addition, each project was extensively documented allowing triangulation via secondary data. Finally, as one of the largest companies in the behavioural design domain over 40 projects were accessible to the research team, providing a foundation for both qualitative and quantitative analysis.

\subsection{Approach}

Prior to the main research phase a pilot study was conducted examining a current project in depth in order to fully understand the working practices and terminology used by the case company. The research team worked with the company for a period of five months in order to establish a trust relationship and ensure wider understanding of the findings in context. Based on this, the number of projects to be reviewed, and the number of elements to be considered 
a structured interview approach was selected (Robson, 2002) (see Structured Interview Guide). Structured interviews were appropriate for two main reasons. First, the number of possible process frameworks, stages, and activities described in the current literature is diverse and extensive; a structured approach allowed these to be assessed and combined in an efficient and traceable manner. Second, in order to analyse process dynamics and sequence interactions for between 5 and 50 projects a key analytical approach is Qualitative Comparative Analysis (QCA) (Rihoux \& Lobe, 2009). This requires data in a standard structure in order to distil core process features and outcome characteristics.

\section{Project Selection}

Of the 40 available projects only 22 dealt directly with behavioural design. These were broadly split into two categories: those including everything from brief to artefact proposal, and those focused on generating behavioural data including analysis and hypotheses. The second project type provides data for later development of designs, but as separate projects. These projects share the same focus and are relevant in the behavioural design context, providing insight on the early process. Assessment of the projects was carried out based on the project documentation and validated by two members of the core design team in the company. One was used in the pilot study and thus eliminated from the analysis. Consequently, 21 projects were taken forward to the structured interview stage.

\section{Structured Interview Guide}

The structured interview guide was derived from the behaviour change and design process literature in order to provide a framework for integrating elements from both domains. The basis for this guide was the overview of design processes by Wynn \& Clarkson (2005) and Andreasen et al. (2015). Design for behaviour change processes were then integrated based on those sources highlighted in Section 1.2 e.g. Fogg (2009a), Selvefors et al. (2011), and Tromp et al. (2011). The guide was refined based on the pilot study to ensure these elements were understandable to the design team, and were properly contextualised with respect to the working practices in the case company. This resulted in a structured guide with a total of 165 individual stage and activity options covering the breadth of the design literature. In order to derive a stage and activity level characterisation of behavioural design a structured guide coupled with QCA balanced constraint and openness. Here, structure is a fundamental requirement for carrying out analysis of process characteristics, progression patterns, and identifying correlations between process and project success. A common issue with structured analyses is that they constrain the research. This was countered through the pilot study and 
the in-depth casework with the company, which checked the comprehensiveness of the 165 options.

Interviews were conducted face-to-face in two phases. First, interviewees were walked through the structured questions for each project. Second, they were directed to elaborate on issues or changes to the specific stages and activities. This ensured that all relevant activities were reflected in the guide and that there was scope for highlighting salient features relevant to the process at the activity level. Each interview focused on a single project to avoid confusion. Follow up questions were used to clarify results and assumptions in the analysis. These were again project specific and face-to-face.

The guide covered nine main process elements each of which included a number of suboptions. Each question was thus multiple-choice, although interviewees were able to add their own comments if they felt a relevant option was not included. The structured guide is linked to the common process elements distilled from the literature and contextualised with respect to the company's terminology in Table 1. The questions aimed to describe the relationship between each process stage, the behaviour change elements considered, and the associated activities undertaken. Thus the guide brings together behaviour change and design process considerations.

Table 1: Summary of interview questions

\begin{tabular}{|c|c|c|c|}
\hline Process element & No. & Question & Aim \\
\hline $\begin{array}{l}\text { Overall } \\
\text { problem/need }\end{array}$ & 1 & $\begin{array}{l}\text { What was the desired behavioural } \\
\text { output of the project? }\end{array}$ & Determine the aim of the project \\
\hline Desk research & 2 & $\begin{array}{l}\text { What did you investigate during the } \\
\text { desk research? }\end{array}$ & $\begin{array}{l}\text { Determine the aim and scope of the } \\
\text { research phase within the project, } \\
\text { how new knowledge was obtained } \\
\text { and used to specify behaviour }\end{array}$ \\
\hline Analysis 1 & 3 & $\begin{array}{l}\text { From your desk research what did } \\
\text { you find had an effect on the } \\
\text { behaviour? }\end{array}$ & $\begin{array}{l}\text { Determine the behaviour change } \\
\text { strategies identified by the team and } \\
\text { their link to the target behaviour }\end{array}$ \\
\hline Scoping & 4 & $\begin{array}{l}\text { Based on the gathered knowledge, } \\
\text { how did you scope the project? }\end{array}$ & $\begin{array}{l}\text { Determine scoping approach used in } \\
\text { the project and its relationship with } \\
\text { the gathered research }\end{array}$ \\
\hline Field study & 5 & $\begin{array}{l}\text { Which tools/approaches did you use } \\
\text { during the field study? }\end{array}$ & $\begin{array}{l}\text { Determine the type of field work } \\
\text { used and the teams approach to it }\end{array}$ \\
\hline \multirow[t]{2}{*}{ Analysis 2} & 6 & $\begin{array}{l}\text { What tools did you use to analyse } \\
\text { the empirical data from the field } \\
\text { study? }\end{array}$ & $\begin{array}{l}\text { Determine how data was analysed } \\
\text { and handled for further work. }\end{array}$ \\
\hline & 7 & What was the output of the analysis? & $\begin{array}{l}\text { Determine how the team proceeded } \\
\text { based on the analysis }\end{array}$ \\
\hline \multirow[t]{2}{*}{$\begin{array}{l}\text { Intervention } \\
\text { development }\end{array}$} & 8 & $\begin{array}{l}\text { Development of interventions: Did } \\
\text { you make a workshop? Did you } \\
\text { make a prototype? What form did } \\
\text { the intervention have? }\end{array}$ & $\begin{array}{l}\text { Determine how the team developed } \\
\text { the intervention, its form, and any } \\
\text { use of prototyping }\end{array}$ \\
\hline & 9 & Which "triggers" were incorporated & Determine the triggers most \\
\hline
\end{tabular}




\begin{tabular}{|c|c|c|c|}
\hline & & in the intervention? & $\begin{array}{l}\text { commonly used in relation to the } \\
\text { targeted behaviour }\end{array}$ \\
\hline & 10 & $\begin{array}{l}\text { Which approach did you use to } \\
\text { affect the behaviour? }\end{array}$ & $\begin{array}{l}\text { Determine the intervention } \\
\text { strategies most commonly used in } \\
\text { relation to the targeted behaviour }\end{array}$ \\
\hline Testing & 11 & $\begin{array}{l}\text { How did you assess the } \\
\text { intervention? }\end{array}$ & $\begin{array}{l}\text { Determine how the team assessed } \\
\text { and evaluate the intervention's } \\
\text { success }\end{array}$ \\
\hline Reporting & 12 & What did the reporting contain? & $\begin{array}{l}\text { Determine the status of the project } \\
\text { at completion. Confirm the aim of } \\
\text { the project outlined in } Q 1\end{array}$ \\
\hline
\end{tabular}

\section{Assessment of Project Success}

In order to assess the outcome of the project for the involved stakeholders a number of success measured were used, based on Obj. 2:

- Perceived success of the design for the customer: the outcome, uptake, and subsequent adoption by the customer.

- Perceived success of the process for the design team: effective design support, stages, activities, team cohesion etc.

- Perceived success of the process for the company: budget overrun, time keeping, and conflict with customers etc.

The aim of this assessment was to evaluate the success of the process for both the customer and the company i.e. a successful project should both satisfy the customer in terms of the design outcome, and also be on e.g. time and budget.

Interview participants were asked to rate project success with respect to both process and output on a scale of 1-5: Was the project process successful for the team and Has the project customer used your recommendations/implement your interventions? The second question also took into account objective evaluations or testing of the design outcome in the documentation or by the company/customer. Project success for the company was evaluated by the research team on a 1-5 scale based on the qualitative statements given by the interviewees as well as based on the secondary documentary data on project performance e.g. costs and time. For example, in one project an interviewee described the process as being characterised by "lacking time to get deep into the project".

The combined qualitative assessment of success was used in order to support the QCA, which requires a binary success characteristic for synthesising processes. The following classification was applied based on the average score from the three assessments:

- An average score of $<4 \quad \Rightarrow \quad 0$ (no success)

- An average score of $\geq 4 \quad \Rightarrow \quad 1$ (success) 
A project with an average score below 4 was not considered successful for the purposes of the QCA. This resulted in 7 of the 21 projects being deemed 'unsuccessful', shown in Table 2 .

\subsection{Data Collection, Triangulation, and Analysis Approach}

Each of the 21 projects was assessed based on the project documentation before each of the designers involved was individually interviewed. Each project was typically associated with one or two designers as outlined in Table 2. The secondary data was also formatted with respect to the structured interview options. Table 2 gives an overview of the projects and agreement between the various sources used. In total 31 interviews were carried across the 21 projects. Projects reflected four main types, denoted by numbers in Table 2: physical artefacts (1), visual campaigns (2), behaviour optimization (3), and behavioural analysis (4). An overview of the strategies used is given in Section 3.2.

Table 2: Summary of projects and data completeness

\begin{tabular}{|c|c|c|c|c|c|c|}
\hline Project description & 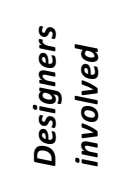 & 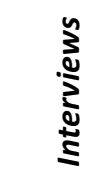 & 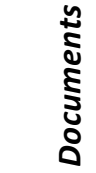 & 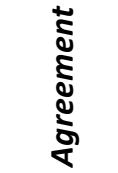 & $\stackrel{\Sigma}{\Sigma}$ & 气ัّ \\
\hline Solutions for a new urban environments & 1 & 1 & $\mathrm{Y}$ & accept & 4 & $\mathrm{Y}$ \\
\hline $\begin{array}{c}\text { Mapping behaviour associated with } \\
\text { housing }\end{array}$ & 3 & 1 & - & accept & 4 & Y \\
\hline $\begin{array}{l}\text { Mapping behaviour and attitude to green } \\
\text { urban spaces }\end{array}$ & 3 & 1 & Y & accept & 4 & Y \\
\hline $\begin{array}{c}\text { Visualising speed information to influence } \\
\text { driver behaviour }\end{array}$ & 1 & 1 & - & accept & 1 & $\mathrm{~N}$ \\
\hline $\begin{array}{c}\text { Influencing mothers to vaccinate their } \\
\text { children }\end{array}$ & 2 & 2 & - & low & 2 & $N / A$ \\
\hline $\begin{array}{l}\text { Behavioural optimisation of a website to } \\
\text { generate higher conversion of viewers to } \\
\text { subscribers }\end{array}$ & 1 & 1 & - & accept & 3 & N \\
\hline $\begin{array}{l}\text { Behavioural optimisation of a website to } \\
\text { generate higher click through }\end{array}$ & 2 & 1 & $\mathrm{Y}$ & accept & 3 & Y \\
\hline $\begin{array}{c}\text { Reducing waste and improve waste } \\
\text { handling }\end{array}$ & 2 & 2 & Y & good & 1 & Y \\
\hline Increasing vaccination rates in children & 2 & 2 & $\mathrm{Y}$ & good & 2 & $\mathrm{Y}$ \\
\hline $\begin{array}{c}\text { Building an exhibition that directs audience } \\
\text { behaviour }\end{array}$ & 1 & 1 & Y & accept & 1 & Y \\
\hline Improving dental care and habits & 3 & 2 & $\mathrm{Y}$ & good & 2 & $\mathrm{Y}$ \\
\hline $\begin{array}{l}\text { Influencing behaviour associated with } \\
\text { resource use }\end{array}$ & 1 & 1 & Y & accept & 4 & $N$ \\
\hline $\begin{array}{l}\text { Numerous approaches to influencing travel } \\
\text { preferences and sell travel packages }\end{array}$ & 2 & 2 & $Y$ & accept & 3 & $N$ \\
\hline $\begin{array}{l}\text { Visualising speed information to influence } \\
\text { driver behaviour }\end{array}$ & 1 & 1 & - & accept & 1 & $\mathrm{Y}$ \\
\hline Reducing speeding behaviour in drivers & 2 & 2 & $\mathrm{Y}$ & good & 1 & $\mathrm{Y}$ \\
\hline $\begin{array}{c}\text { Visualising speed information to influence } \\
\text { driver behaviour }\end{array}$ & 2 & 2 & $Y$ & good & 1 & $Y$ \\
\hline
\end{tabular}




\begin{tabular}{cllllll}
\hline Reduction of piracy & 3 & 1 & $\mathrm{Y}$ & accept & 2 & $\mathrm{~N}$ \\
Increasing voting participation rates & 1 & 1 & - & accept & 2 & $\mathrm{~N}$ \\
Mapping the needs of diabetics & 2 & 1 & $\mathrm{Y}$ & good & 2 & $\mathrm{Y}$ \\
Mapping the behaviour of diabetics & 2 & 2 & - & good & 4 & $\mathrm{Y}$ \\
Health profiling and influence health & 2 & 2 & - & good & 4 & $\mathrm{Y}$ \\
related behaviour & & & & & & \\
\hline
\end{tabular}

Based on the assessment of agreement between sources summarised in Table 2 one project was removed from the analysis due to low agreement between the interviews (highlighted in the agreement column). The findings at this stage were presented back to the case company and further clarification sought where agreement was only acceptable. In total 20 projects were brought forward into the analysis phase, selected for the high level of data consistency and completeness.

\section{Qualitative Comparative Analysis}

QCA was chosen because it allows for the systematic comparison and synthesis of complex processes (Rihoux \& Lobe, 2009). This is particularly relevant for this study where there are too many variables to be decomposed quantitatively. QCA allows for the distillation of combinations of parameters leading to a common result (Rihoux, 2006). A major advantage of QCA is the ability to work with smaller data sets with a large number of varied cases (Jordan, Gross, \& Javernick-Will, 2011). QCA also supports the analysis of causal links between conditions, in this case how the specific process stages contribute to overall project success. This makes it an ideal approach when a number of conditions (stages/activities) need to be integrated in a single analysis.

QCA follows a number of steps, which allow for the distillation of a core process that has a causal relationship with project success. This takes into account both positive and negative cases, with positive cases adding weight to the causal relationship and negative cases diminishing it. Further, due to the nature of QCA the distilled process is robust across the range of project characteristics outlined in Table 1 (see Obj. 1) (Rihoux \& Ragin, 2009). The basic steps in QCA are outlined below to aid understanding of the results.

Step 1: Identify the outcome (see assessment of success) and subsequently identify both positive and negative cases (see Table 2). Based on this and relevant theory identify the causal conditions relevant to the outcome (see Structured Interview Guide). Streamline the conditions in order to reduce the number of possible process combinations (see Structured Interview Guide, Table 1).

Step 2: Construct a "truth table" using the causal conditions from Step 1. This sorts cases by the combinations of conditions in each case. All possible combinations of conditions are then 
considered. Assess the consistency of the combinations with respect to the outcome $(100 \%$ or $0 \%$ represent perfect consistency). Identify contradictory combinations and compare across in order to identify decisive differences between positive and negative cases.

QCA provides a core process distilling the specific stages and activities associated with project success, which can then be further interrogated in order to explore the key characteristics of successful projects. QCA allows for assessment of causation even if it is complex, which is in contrast to typical qualitative approaches where successful and unsuccessful projects are compared individually (Rihoux, 2006). For this analysis the standard QCA software Compasss was used (Rihoux, Thiem, Rubinson, \& Defacqz, 2016).

\section{$3 \quad$ Results}

Results are reported in two phases. First, the overall process stages are distilled based on the QCA. Second, the activities within each stage are evaluated.

\section{1}

Overall Process Synthesis

From the 20 projects the initial QCA highlighted three major combinations of causal conditions. Grouping 1 reflected the process distilled from behavioural analysis (Table 2) type projects and thus predominantly early process stages. Groupings 2 and 3 spanned the range of recorded project characteristics and stages (Table 2). However, Grouping 3 was closely linked to IT-oriented projects. These initial groupings are outlined below:

1. Behavioural analysis type projects resulted in a distilled process combining stages 1-4.

2. A second distilled process combined stages $1-6$, bringing together $20 \%$ of projects.

3. A third distilled process combined stages $1-4,7$, and 8 , bringing together $40 \%$ of projects.

The three groupings shared common stages and activities associated with experimental processes, and were aligned in terms of positive/negative process features. For example, in all cases stages 1-4 were a pre-requisite for success, while combining stages 1-6 gave an $83 \%$ probability of success. Interviewees were consistent in characterising their work as a combined scientific and design endeavour. The fact that these initial groupings align in terms of early process stages, basic foundation, result consistency, and key project characteristics means that they can be further distilled into a core behavioural design process.

These results are summarised in Figure 2, which shows the three groupings as well as illustrating their synthesis into the full process. This is robust across all the characteristics described in Table 2, and represents a normative behavioural design process. Thus the QCA provides an overview of the combined behavioural design process stages (Figure 2). However, 
in order to understand why this combination is causally linked to project success it is necessary examine the associated activities in more detail (see Section 2.3).

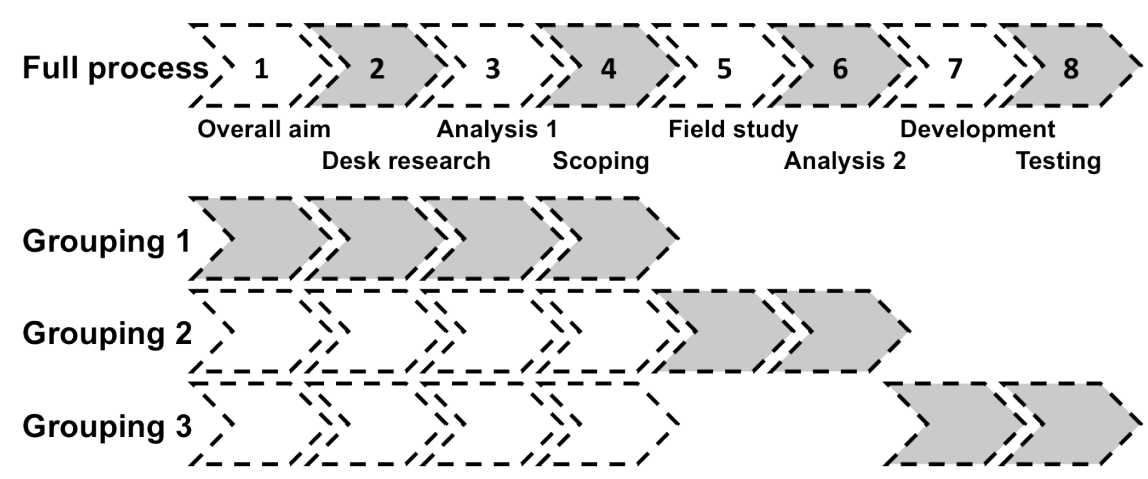

Figure 2: The three initial groupings and their synthesis into the full process

\subsection{Detail of Process}

This section describes the stages linked to project success in more detail, in order to illustrate the iterative activities within each. These are derived from the QCA as well as additional quantitative and qualitative comparison of successful/unsuccessful projects. To be included here activities must be: identified in the QCA distillation (based on the widely used acceptance threshold of 75\% (Rihoux \& Lobe, 2009)); quantitatively associated with success (based on positive Pearson correlation with significance $p<0.05$ (Walker, 2010)); qualitatively linked to success in terms of known design for behaviour change theory. Here positive correlation was considered sufficient, as strong correlation would not be expected in this context where there are multiple interacting factors (dealt with by the QCA).

\section{Stage 1: Overall Aim}

Results from this stage show that project success is dependant on alignment between the project aim - defined with respect to target behaviour - and mapping of the behavioural elements associated with the behaviour/product (Section 1). Key to this is describing the target behaviour both: tangibly, such that practical factors and similar behaviours can be identified in the subsequent research stage; and theoretically, in order to identify descriptive models pointing to possible solution spaces (Section 1.1). In particular, theoretical description was found to be key, however, tangible understanding should not be ignored given the need for real world testing in Stage 8 . Where both perspectives are described probability of success is $75 \%$. However, where tangible or theory is considered in isolation probability of success is reduced to $20 \%$ and $70 \%$ respectively. This applies to projects targeting both long and shortterm behaviour change. 
In addition clarity in definition of the problem behaviour was an important determinant of project success. This was required in addition to more traditional problem statements associated with customer or user needs. For example, several projects achieved this by building on the link between priming and self-construal. Behaviours were defined in context and described with respect to both local and national norms. This then allowed for a targeted behaviour mapping to be developed, which proved an effective means for guiding subsequent process stages.

\section{Stage 2: Desk Research}

Successful projects drew heavily on scientific literature, and combined the whole range of available research options. Within these the following approaches were most strongly correlated with project success: systematic review of scientific literature, defining global and local behavioural trends, systematic review of existing products and market solutions, consulting with relevant behavioural experts. This highlights the importance of multifaceted assessment of the target behaviour. In particular, 12 of the 14 successful projects used systematic review and meta-analytical assessment of previous outcomes. For example, a number of projects built on meta-analytic data describing image based priming in order to more effectively target their design work.

\section{Stage 3: Analysis 1}

Results from desk research were typically brought together in relation to theoretical constructs such as self-construal and implicit memory. This resulted in a detailed characterisation of the factors associated with the target behaviour e.g. social norms, social context, and physical environment. Successful projects also incorporated considerations of users' ability to carry out the new behaviour and motivation to do so. In addition, behaviour specific analysis was carried out in each project based on the prior research work.

\section{Stage 4: Scoping}

Successful projects combined extended behavioural problem definition and definition of measurable solution requirements. Definition of the behavioural problem focused on specification with respect to the results of analysis 1 . The translation of this definition into measurable behavioural solution requirements then formed the foundation for subsequent field study, testing, and intervention assessments. Interviewees emphasised that it was not sufficient to simply define a behavioural problem statement. Further, the creation and testing of hypotheses was considered key to maintaining the tight focus required for designing 
behavioural interventions e.g. "A rewarding explorative investigation starts out with the posing of hypotheses, which allows us to state the right questions for the problem."

\section{Stage 5: Field Study}

An important predictor of field study success was the prior effectiveness of desk research and scoping, particularly the production of specific hypotheses. The main function of field study was to extend understanding and provide quantitative assessment hypotheses associated with the proposed intervention. Successful projects combined both qualitative and quantitative assessments. Qualitative interviews were used to investigate users' perceptions of behaviour, their attitudes, and their intentions. However, these were not used as a basis for hypothesis testing because as an interviewee stated "People have a tendency to state the answer that expresses who they would like to be, and not who they are". Instead observations were used to gather and quantify data with respect to the target behaviour. This provided a quantifiable baseline against which potential designs could be tested for effectiveness later in the process, via e.g. comparative experimental studies: "we combine hard and soft data to give a solid mapping of the target group's behaviour as well as a precise effect measurement of the designed interventions."

\section{Stage 6: Analysis 2}

Results from the field study were analysed on a project-by-project basis, and used to carry out several important scoping and refinement activities. Successful projects combined: premise, behavioural frameworks, and re-framing. Premise describes the task of refining the overall direction of the design process with respect to both behaviour and the artefact to be designed. The outcome of this activity is a proposition for how the final designed artefact will actually change the target behaviour. This brings together elements from traditional product development and behavioural analysis, refining the solution requirements. These requirements are then used as the basis for describing a detailed behavioural framework, which defines the inputs, contextual factors, independent, and dependant variables associated with the intervention. This provides a detailed scientific foundation for the design. Finally, reframing describes the process of combing the previous activities into a mapping of the final target behaviour in relation to the design artefact.

\section{Stage 7: Development}

Successful projects combined: behavioural strategy definition, behavioural trigger definition, intervention deployment, and intervention assessment. These were refined iteratively via extensive prototyping. The behavioural strategies used were project specific but do highlight 
some more common and successful approaches, summarised in Figure 3. Approaches were defined by the company and thus are at differing levels of detail. Here, it is important to note that as with the stages/activities these results were derived semi-inductively in line with the structured interview approach. An initial list of strategies/triggers was compiled from the same literature used for the process elements, and interviewees were able to add new entries as required as described in Section 2.2. These results confirm that the projects assessed did in fact focus on unconscious behaviour change strategies.

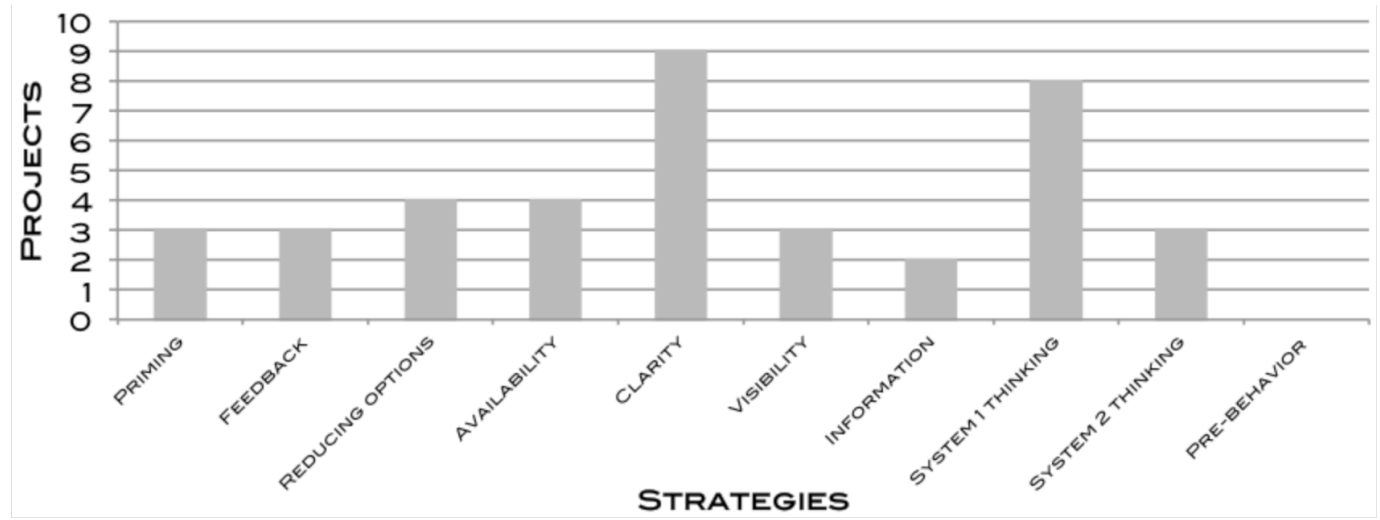

Figure 3: Use of behaviour change strategies

Breaking down the strategies, a wide range of triggers were found, summarised in Figure 4. In all cases the interviewees emphasised that triggers were highly strategy and context dependant and thus relied on effective information from prior research and scoping stages.

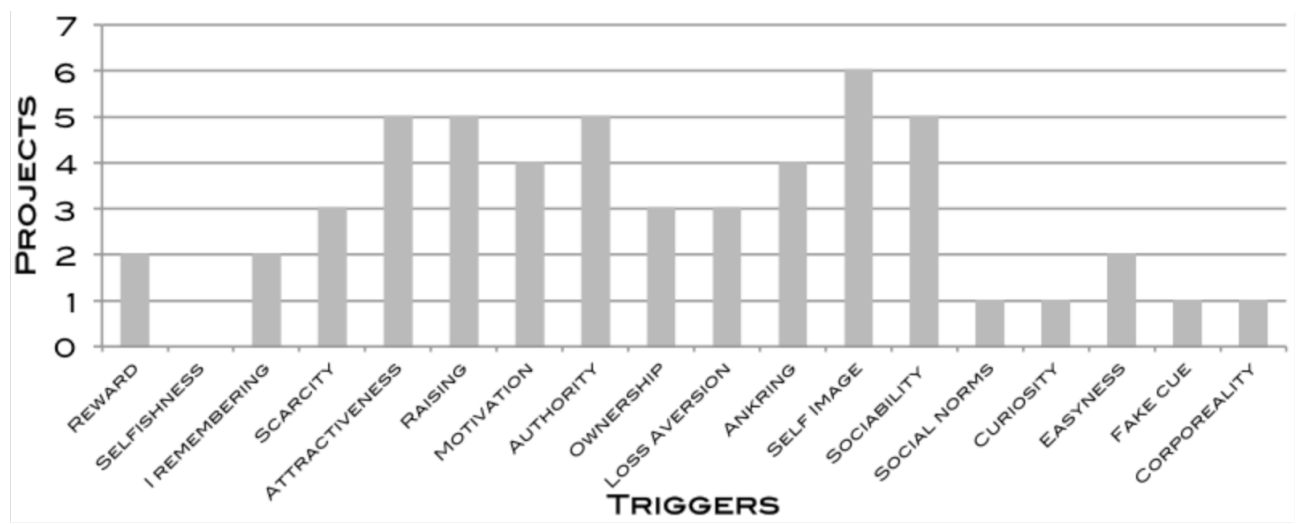

Figure 4: Use of behaviour triggers

\section{Stage 8: Test}

Inclusion of testing increased the probability of project success to over $60 \%$, and was iteratively linked to development. The aim of this stage was to quantitatively verify the impact of the proposed design in comparison to the baseline data from field study. This was key to demonstrating the effectiveness of the behavioural interventions, and differentiating real from 
placebo effects. This is important as prediction of effect is difficult due to the highly contextual nature of behaviour. Further, this played a key role in ensuring there were no major negative effects and that ethical considerations were working in practice. During iterative testing and assessment of the final intervention it was found that successful projects combined: models, design refinement, and quantitative methods.

Models describe the process of explicitly assessing the feasibility of the adopted strategy with respect to: time, resources, effect, and scalability. The design refinement activity then finalised the prototype proposal and requirement specification for the artefact to be designed. This combined behaviour and traditional product considerations, and fed into the normal product development process. This was also used to reflect on the success of the behavioural specification produced earlier in the process and to define the specific design elements related to the behavioural solution. Both of these activities were supported by quantitative analysis based on repeated experimental and real world testing. For example, one project focused on user behaviour surrounding littering; here iterative experimental studies were carried out in conjunction with pre-/post-intervention observation of behaviour at the intervention site.

\subsection{Unsuccessful Projects}

Although QCA accounts for unsuccessful projects in the synthesis of positive and negative influences (see Section 2.3), it is important to consider any specific characteristics of unsuccessful projects. Here, two major issues were highlighted. First, failure to find appropriate behavioural models and analytical data in the scoping stages (1-4) reduced the effectiveness of subsequent design efforts. Lack of behavioural models detrimentally impacted focusing of the explorative work, and lack of prior intervention data meant that the solution space was difficult to define. Second, a number of unsuccessful projects were forced to carry out stages out of sequence in comparison to Figure 2. This was often driven by constraints of data collection or implementation. Key to behavioural design is the systematic building of explanatory models and data surrounding an intervention. Thus disrupted stage orderings had a substantial negative impact on project performance, with the design team often having to do re-work in order to bring the project back on track. These insights support the overall results described in this section, and point to process coordination issues as one of the major reasons for project failure. This also serves to highlight the need for design support in this domain.

\section{$4 \quad$ Synthesis of the Behavioural design Process and Discussion}

The Behavioural Design process takes the form of a stage-gate sequence moving from divergent (explore and define behaviour) to convergent (affect behaviour) elements. The first 
element contains two major stages: behaviour mapping and field work, while the second contains: intervention development driven by iterative testing and refinement, illustrated in Figure 5. The overall process combines a structured sequence of stages, with iterative activities within each. This follows a combined process approach as described by Wynn \& Clarkson (2005). Each stage is named with respect to generic design process terminology (Wynn \& Clarkson, 2005), rather than the case specific terminology used in Section 3.

The proposed process links to aspects of a number of conscious models (Fogg, 2009a; Lilley, 2009; Selvefors et al., 2011). In particular it elaborates and structures the front end behaviour mapping in comparison to e.g. Selvefors et al. (2011), and complements Fogg's (2009a) suggested iterative testing and refinement phase. The focus on unconscious strategies demands substantially more rigorous behaviour mapping and specification of testable behavioural hypotheses, in comparison to conscious strategies. Hence the elaboration in comparison to e.g. Selvefors et al. (2011). Further, testing and iterative refinements are key to both conscious and unconscious approaches and are essential for ensuring that interventions operate as desired. Hence the relative alignment across models. As such, a key feature of the proposed process is the focus on designing based on a deep scientific assessment of the problem behaviour and underlying psychological constructs (Section 1.1). This goes beyond only technologically facilitated behaviours, and is a key correlate of project success (Section 3.2). This builds on specific description of both the underlying behavioural theory and the tangible aspects of the behaviour e.g. ability or motivation. In particular, effective integration of theory allows designers to target mediating factors such as social norms, as well as to identify extant data, which supports both meta-analysis and ideation. However, critical to effective integration of theory is an open approach i.e. the theory most appropriate to a given problem should be used as the foundation for the design. As such, Behavioural Design specifically complements the excellent recent work by Tromp \& Hekkert (2016), who describe the overarching Social Implication Design (SID) method. While the SID method focuses on the interface between individual and society the proposed behavioural design process explicitly details the development of the behaviour change intervention itself. Further, both SID and behavioural design build on an open approach to theory integration. As such, it would be possible to integrate these two propositions, with each detailing different aspects of the core design process. 


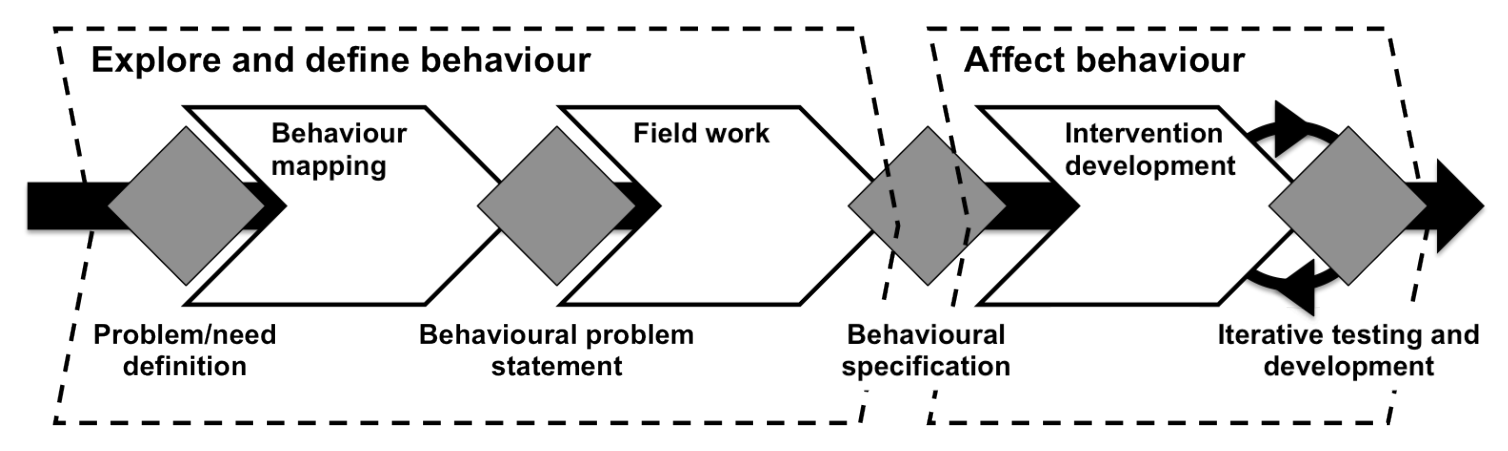

Figure 5: The Behavioural Design process synthesising the theoretical and empirical results

The behavioural design process is compatible with traditional product development processes and methods, allowing it to be incorporated into product development as part of e.g. the stage gate process described by Ulrich and Eppinger (2003). Behavioural design provides an alternative path through the 'Concept Development' phase. Comparing the proposed process to typical stages within this phase it is possible to see how behavioural design interacts with more traditional design processes, as illustrated in Figure 6. In this way, behavioural design can be aligned with different higher level processes in order to be applied in domains outside product development e.g. by integrating it with a systems design process.

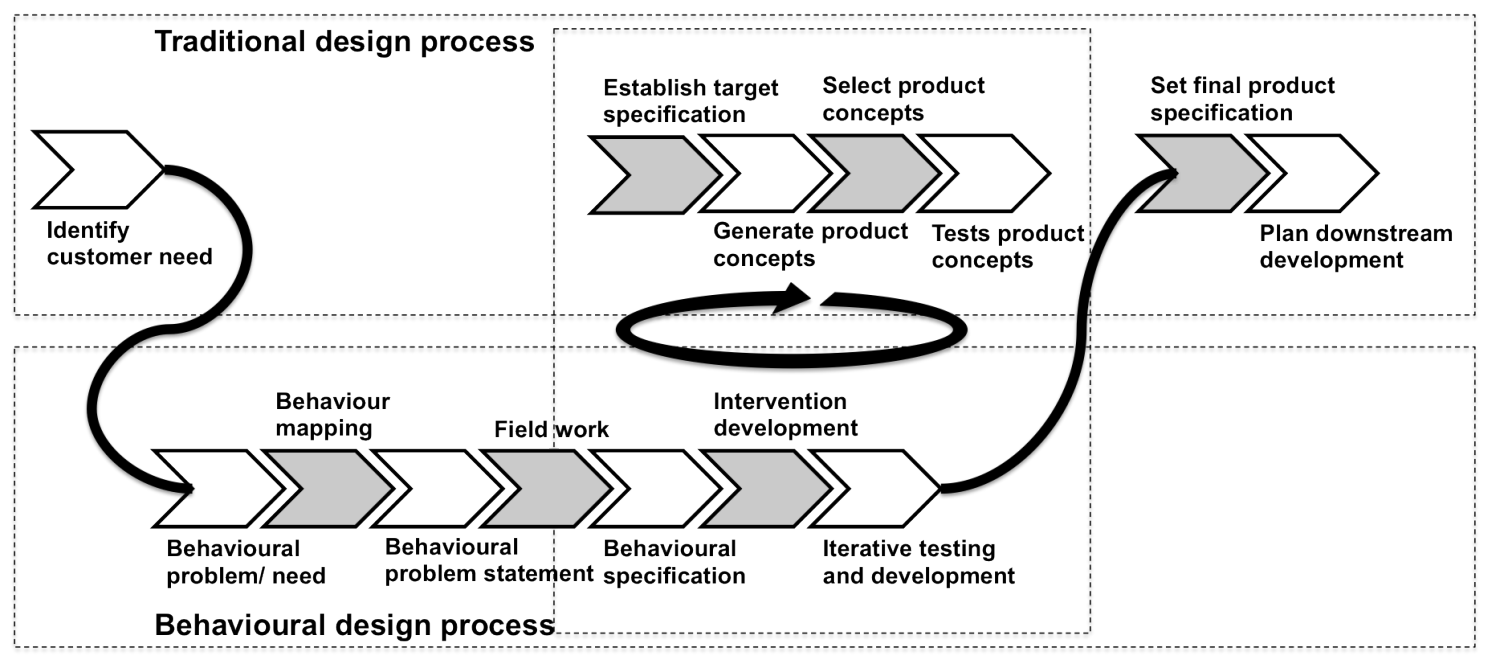

Figure 6:The behavioural design process in relation to traditional design process stages

\subsection{Behavioural Design Process Stages}

\section{Problem/need Definition}

The starting point for behavioural design is the definition of the behavioural problem or need. This takes place subsequent to or in parallel with the wider definition of the customer need. For example, one project identified a problem with drunken people littering in a busy pedestrian area. A number of behavioural elements were considered: the practicalities of 
directing waste disposal, awareness and access to bins, public awareness of the problems stemming from littering, and the behaviour of littering itself.

The output from this gate is the initial aim and scope of investigation with respect to the target problem. In the littering example a decision was made to address behaviours associated with littering, rather than behaviours associated with the selection of products with less wasteful packaging. In either case it is important to be able to identify a behaviour or specific sequence of behaviours that form the focus of the initial research. Selection of scope at this stage should focus on the ability to influence the behaviour through the planned artefact. For example, if the behaviour is associated with littering it might be possible to influence this through cues in the street environment; however, it might be less tractable given a software-based solution. Thus the product, behaviour, potential strategy, and intervention should co-evolve. In particular, when targeting priming type interventions and their link with social norms, it is important that people are e.g. aware of the negative social connotations of littering. Explicitly identifying both of these issues is critical to project success. The specification of aim and scope in both theoretical and tangible dimensions is a key feature of behavioural design, which is less prominent in extant approaches (Fogg, 2009a; Selvefors et al., 2011).

\section{Behaviour Mapping}

This stage systematically details the elements associated with the behavioural problem identified in problem/need definition e.g. social norms, environment, social context, and personal factors. This builds directly on the research based processes found in the psychology literature e.g. assessment of trends, meta-analysis, user profiling etc. Both theory and the findings from the study highlight the fact that effective behaviour mapping requires integration of numerous sources of information dealing with all aspects of the behaviour. This is particularly important as behaviours are typically considered to be complex and contextual and thus require mapping for each new intervention (Dolan et al., 2014; Fogg, 2009b).

Although it is possible to draw on previous designs and approaches at this stage (N. Cross, 2008; Ulrich \& Eppinger, 2003), the contextual nature of behavioural interventions means that this must be applied with caution. However, one advantage of behavioural design is in examining how robust certain intervention types are across products or contexts. Here identification and distillation of meta-analytical results is key to shaping the initial design work (Section 3.2). For example, when considering the type of priming in the littering project the design team examined data on the effectiveness of various primes and the link between the desired outcome and the target behaviour. 
Assessment of past solutions must take into account shifts in global or local trends. For example, social norms and context are not static and care must be taken to assess how their changing over time, and across populations, might affect a planned intervention (Sunstein, 1996). These also link to personal motivations, attitudes, and emotional associations (Dolan et al., 2014; Loewenstein, Weber, Hsee, \& Welch, 2001). Here, key iterative activities are multifaceted behaviour mapping, the development of behavioural frameworks, and linking these to implicit design features. These are distinct to behavioural design in comparison to e.g. Fogg's (2009a) or Lilley's (2009) frameworks. The behavioural framework is required in order to shape quantitative experimental testing of interventions, due to the relative significance of e.g. placebo effects, in this domain.

\section{Behavioural Problem Statement}

The outcome of this gate is a behavioural problem statement, which sets the stage for further exploration of the target behaviour. A key difference from previously suggested problem statement activities is the formulation of testable hypotheses related to the core elements of the behaviour and intervention, linked explicitly in the behaviour framework. The aim of the hypotheses is to define and test the assumptions underpinning the causes of the behaviour with respect to e.g. the environmental cues, social norms and context, and personal perceptions. Deciding on these elements is essential before proceeding with the field work as they define the baseline data to be collected. For example, in the littering project visual cues were used to impact behaviour, however, it was necessary to define a number of hypotheses in order to assess the effectiveness of the specific intervention in comparison to other changes implemented e.g. public awareness.

Similar to traditional processes this gate serves to clarify and agree the key features of the project and its subsequent objectives. However, the ambiguity of behavioural problems demands a focused experimental approach in order to ensure the link between intervention and behaviour change is robust. This gate is also important for clarifying the role of the intervention within the wider strategy for the team and with the customer.

\section{Field Work}

The goal this stage is to both extend the general understanding of the target behaviour and establish baseline data for later comparative testing. In addition, hypotheses regarding the preconditions, context, and cues associated with the target behaviour are resolved at this stage i.e. what is causing the behaviour and what might influence it. As these two aims are distinct, a combination of qualitative and quantitative techniques is recommended. 
Qualitative studies give insight into user perceptions and attitudes, as well as helping contextualise the behaviour with respect to social norms and context. This serves a similar role to more traditional user involvement studies, except with a behavioural focus (Sanders \& Stappers, 2014). Quantitative studies allow the design team to measure behaviours and influences through observation and testing of casual relationships, building on classical comparative designs (Kirk, 2009). The explicit combination of qualitative and quantitative elements, particularly experimental approaches, is a key distinguishing feature of behavioural design. This is supported by the strong link between joint experimental/observation studies and project success (Section 3.2). This is particularly important because unconscious behaviours are highly context dependant and thus a link needs to be drawn between laboratory and real world settings. These studies should be used to refine the behavioural mapping and define measurable criteria against which intervention efficacy can be assessed. In the littering example, qualitative data was gathered on public perceptions and perceived social norms through interviews, and combined with quantitative description of pre-/postintervention observations, as well as experiments comparing different interventions.

\section{Behavioural Specification}

This gate is related to the specification and product conceptualisation activities in traditional product development processes (Figure 6). Here the behavioural specification is a distinct additional activity critically linked to project success, playing a major role in 13 out of 14 successful projects. For example, this formed the foundation for ideation and testing activities in the littering project and helped guide the overall strategy in combination with more traditional design considerations e.g. bin usability.

The outcome of this gate should be the selection of a single defined target behaviour or linked sequence of behaviours, accompanied by baseline data from the field work. This forms the foundation for subsequent intervention and product testing. The behavioural requirements specification describes the specific factors that the intervention must take into account from both the behavioural and technical product perspectives. This establishes target functions with respect to the behaviour/intervention that must be fulfilled by the product (Ulrich \& Eppinger, 2003). As such, this gate extends and refocuses traditional requirement specification use ( $\mathrm{N}$. Cross, 2008) and subsequently forms the core of the following development and testing activities.

It is important to note that if the overall aim involves a number of related behaviours it is at this gate where these are explicitly separated into individual design processes. For example, if 
three target behaviours were found to be related, the process would split into three parallel streams, each of which would progress through the remaining stages before being brought together in the final product, illustrated in Figure 7. This can also include the integration of other parallel behaviour change strategies, such as Fogg's (2009a) eight stage process.

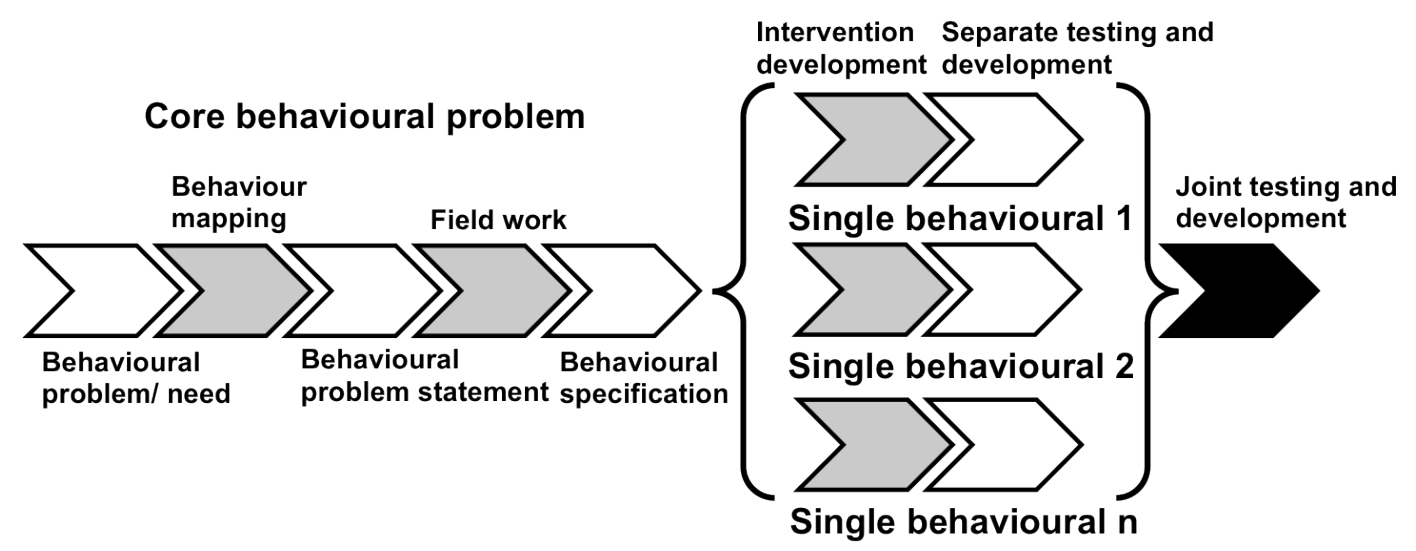

Figure 7: Parallel development targeting multiple individual behaviours

\section{Intervention Development}

As with the behavioural specification intervention development also informs parallel product development (Figure 7). The main aim of this stage is to propose interventions aligned with the selected strategy, test their effects with respect to the baseline data (field work), iteratively develop their effectiveness, and ultimately combine the intervention with the technical product design. Here, it is important to retain the validity of the intervention when it is combined with the product. The results show these elements to be highly behaviour specific. As such, the design team should consider all possible perspectives outlined in the behaviour mapping (Lockton et al., 2008; Michie et al., 2008). This is particularly important in implicit interventions where effects on behaviour are subtle and dependant on a wide range of additional factors e.g. culture.

In terms of intervention assessment, beyond the traditional scientific approaches to measurement of effect size and significance, practical assessment should focus on the feasibility of the intervention in terms of time, resources, effect, and scalability. The overall efficacy of the intervention should be related to the behavioural requirements specification in order to ensure overall alignment with the wider strategy.

\section{Iterative Testing and Development}

The final iterative gate is only passed when the design team is satisfied that the proposed intervention is effective and ethical, the combined product/intervention strategy fulfils the 
behavioural requirement specification, and the final concept is ready for downstream development (Figure 6). As such, this is the final gate in the behavioural design process.

The final proposal (combing the intervention and product elements) should be validated experimentally, ideally in situ, but alternatively in a controlled setting. Thus iterative testing is key to refining the overall design and ensuring ethical and behavioural compliance. The aim is to establish how the solution functions with respect to the target behaviour, audience, and context. This is an important feature of behavioural design due to the nature of implicit interventions where more traditional evaluations of user perception or behaviour are not sufficient in isolation.

\subsection{Behavioural Considerations and Mindset}

For implicit strategies the target behaviour needs to be embedded in the automatic system of the brain (Bargh, Chen, \& Burrows, 1996). For example, priming cannot influence behaviour in areas that are unfamiliar to the subject (Fitzsimons, Chartrand, \& Fitzsimons, 2008). As such, careful consideration must be given to eliciting and deploying cues relevant to the influencers of behaviour e.g. social norms. Further, in order to promote a specific behaviour, the end state of the behaviour must have positive associations for the subject. An end goal that is negatively perceived by the subject will not be successfully adopted (Fitzsimons et al., 2008). To be effective the impact on the subject must be kept implicit and relevant, to maintain freedom of choice and reduce awareness (Kay et al., 2004). This is a key differentiating feature of behavioural design, and was also identified as a major component of project success in the case company (Section 3.1).

Finally, although the behavioural design process is complementary to traditional design practice it is essential that the design team focus on the behavioural aspects first, and allow these to drive the definition of the product, rather than adopting a more technical, function driven mindset. The complexity and specificity of behavioural design is such that behaviour must be kept in focus throughout the product development process. This is the driving mindset through which methods and process elements are combined, and is a key part of successfully using the proposed process (Andreasen et al., 2015). At its core, this mindset draws on the scientific process of proposition and experimentation, and uses this as the common element around which design stages are arranged. This mindset is essential when targeting unconscious behaviours, and drives many of the features of behavioural design.

\subsection{Ethical Considerations}


Although ethical issues are not the focus of this work, it is impossible to discuss behavioural design without also considering ethics. In particular there are a number of possibilities for ethical abuses even where the designer is well intentioned. As such, there is a need for a continuous and open debate on the ethical use of persuasive approaches, both conscious and unconscious (Oinas-kukkonen \& Harjumaa, 2008). In this case the widely recognised guidelines provided by Berdichevsky and Neuenschwander (1999) are suggested as a general framework for both researchers and designers in this domain. More specific to the design context Lilley and Wilson (2013) discuss the ethical considerations associated with design for sustainable behaviour, and how these can be managed by a designer.

In the context of the case company ethical considerations form a major part of their design process. At a mindset level the company has produced a specific ethical guideline that all employees are required to be aware of. This brings together the works highlighted above and contextualises them within the company. The development of this guideline was a significant strategic effort by the company and represents a major commitment to ethical standards. Further, ethical issues are systematically reviewed at each stage of a project and compliance with the ethical guideline is a prerequisite for progression.

\section{$5 \quad$ Implications and Limitations}

This work provides a number of implications for design researchers and practitioners.

\subsection{Implications}

The proposed behavioural design process brings together elements from product development, psychology, and the wider design for behaviour change literature. This adds an important new dimension for influencing user experience by bridging implicit effects and product design. This closes the gap in current design process literature and links to efforts to support the integration of behavioural effects in complex technical products via e.g. design affordances (Villa \& Labayrade, 2014).

QCA offers a potentially powerful method for distilling empirically grounded design processes, which has seen little use in the design literature (reviewing the core design journals listed in Section 1 no prior uses of QCA were identified as of 2016). In particular, the ability to distil a core process from an initial list of 165 possible stages and activities points to the potential for this approach. Further, the fact that the distilled process elements were supported by the secondary analysis of correlation and significance lends substantial support to the potential efficacy of QCA. 
Finally, the operationalization and integration of implicit behaviour change strategies and design practice provides an important new approach for design teams targeting user behaviour through product design. In particular, the proposed process provides a structured means for combining methods from a number of domains to achieve more cohesive design results.

\subsection{Limitations}

The proposed behavioural design process is necessarily at the stage/activity level. Although this provides an important guide (process and mindset) for design work there is need for further development of more specific insight and methods at the activity level. As such, despite there being significant further work required in this domain the proposed process provides a necessary first stage in developing a cohesive body of behavioural design methods.

The sample included 20 projects of varying complexity, type, and outcome (Table 2); however, they were all drawn from a single company. Further work is thus needed to explore and refine these findings in different industrial settings. In particular, the case company is one of a very small number of companies focused on behavioural design in Europe. As such, an important area for further study is the processes used by design teams integrated in larger departments not necessary with a dedicated behavioural focus. This work provides a logical foundation for this investigation and spans a range of project types reducing the likelihood of subject area impacting process applicability.

Finally, there is a need for further work bridging ambient and product influences on user behaviour in the engineering design context. Specific effort is needed to synthesise behavioural design, persuasive design, and other behaviour change approaches in order to provide tailored support across the spectrum of behavioural phenomena (Tromp, 2013). This could link to more traditional engineering design to support combined strategies influencing users through System 1, System 2, and technical constraints.

\section{Conclusion}

The presented work draws on the psychology, persuasive design, and product development literature as well as a study of 20 behavioural design projects to propose the Behavioural Design process, which integrates unconscious behaviour change strategies and design practice. The proposed process complements persuasive design and product design research by closing a key gap in current process support for designers. This work moves 'nudging/priming' from the preserve of psychologists into a form accessible to engineering design teams. Further, the stage/activity level characterisation of the behavioural design process allows for its integration 
with existing product development processes. Finally, the wide range of project types examined in the case study supports the robustness of behavioural design across application areas. Thus the proposed behavioural design process is an explicit, empirically supported, answer to the aim: Distil a behavioural design process empirically linking process framing, stages, and activities, to successful process outcomes. This is robust across intervention types and other factors such as team size. However, as with all process models, following the proposed process does not guarantee success, rather it offers a guide for the design team.

Areas for further research are the adaption or development of lower level methods to support the activities required by unconscious behavioural change strategies. In particular, creativity and intervention synthesis are key challenges in current behavioural design practice. Further, this work highlights the opportunity for researchers to study the interface between persuasive and behavioural design in the engineering design context (Tromp, 2013), where non-technical approaches have, to-date, seen limited uptake. Finally, further work is needed to examine the long-term affects of behavioural design projects, and their real world impact on behaviour.

\section{References}

Abrahamsen, W., Steg, L., Vlek, C., \& Rothengatter, T. (2005). A review of intervention studies aimed at household energy conservation. Journal of Environmental Psychology, 25(3), 273-291.

Andreasen, M. M., Thorp Hansen, C., \& Cash, P. (2015). Conceptual design: Interpretations, mindset, and models. Springer.

Bargh, J. A., \& Chartrand, T. L. (2000). Studying the Mind in the Middle: A Practical Guide to Priming and Automaticity Research. In Handbook of Research Methods in Social Psychology (pp. 1-37). New York: Cambridge University Press.

Bargh, J. A., Chen, M., \& Burrows, L. (1996). Automaticity of social behavior: direct effects of trait construct and stereotype-activation on action. Journal of Personality and Social Psychology, 71(2), 230-244.

Berdichevsky, D., \& Neuenschwander, E. (1999). Toward an ethics of persuasive technology. Communications of the ACM, 42(5), 51-58.

Bhamra, T., Lilley, D., \& Tang, T. (2008). Sustainable use: changing consumer behaviour through product design.

Bhamra, T., Lilley, D., \& Tang, T. (2011). Design for Sustainable Behaviour: Using Products to Change Consumer Behaviour. The Design Journal, 14(4), 427-445.

Blessing, L. T. M. (1994). A process-based approach to computer-supported engineering design.

Cialdini, R. B. (2007). Descriptive Social Norms as Underappreciated Sources of Social Control. Psychometrika, 72(2), 263-268.

Cox, W. T. L., Abramson, L. Y., Devine, P. G., \& Hollon, S. D. (2012). Stereotypes, Prejudice, and Depression: The Integrated Perspective. Perspectives on Psychological Science, 7(5), 427449.

Cross, N. (2008). Engineering design methods: strategies for product design. Wiley and Sons, 
Inc.

Cross, S. E., \& Madson, L. (1997). Models of the self: self-construals and gender. Psychological Bulletin, 122(1), 5-37.

De Young, R. (1993). Changing Behavior and Making it Stick: The Conceptualization and Management of Conservation Behavior. Environment and Behavior, 25(3), 485-505.

DeMarree, K. G., Wheeler, S. C., \& Petty, R. E. (2005). Priming a new identity: self-monitoring moderates the effects of nonself primes on self-judgments and behavior. Journal of Personality and Social Psychology, 89(5), 657-671.

Dolan, P., Hallsworth, M., Halpern, D., King, D., \& Vlaev, I. (2014). Mindplace: influencing behaviour through public policy.

Dwyer, W. O., \& Leeming, F. C. (1993). Critical Review of Behavioural Interventions to Preserve the Environment - Research Since 1980. Environment and Behavior, 25(3), 275-321.

Evans, J. S. B. T. (2008). Dual-processing accounts of reasoning, judgment, and social cognition. Annual Review of Psychology, 59, 255-278.

Fitzsimons, G. M., Chartrand, T. L., \& Fitzsimons, G. J. (2008). Automatic Effects of Brand Exposure on Motivated Behavior: How Apple Makes You "Think Different." Journal of Consumer Research, 35(1), 21-35.

Fogg, B. J. (2009a). Creating Persuasive Technologies: An Eight-Step Design Process. In Persuasive Technology. Fourth International Conference, PERSUASIVE 2009 (pp. 1-6). Claremont, CA, USA, CA, USA.

Fogg, B. J. (2009b). The behavior grid: 35 ways behavior can change. In Proceedings of the 4th international Conference on persuasive technology (pp. 1-5).

Fogg, B. J., \& Hreha, J. (2010). Behavior wizard: a method for matching target behaviors with solutions. Persuasive Technology, 6137, 117-131.

Francis, J. J., Stockton, C., Eccles, M. P., Johnston, M., Cuthbertson, B. H., Grimshaw, J. M., ... Stanworth, S. J. (2009). Evidence-based selection of theories for designing behaviour change interventions: using methods based on theoretical construct domains to understand clinicians' blood transfusion behaviour. British Journal of Health Psychology, 14(4), 625-646.

Godin, G., Bélanger-Gravel, A., Eccles, M., \& Grimshaw, J. (2008). Healthcare professionals' intentions and behaviours: a systematic review of studies based on social cognitive theories. Implementation Science : IS, 3(36), 1-12.

Greening, L. A., Greene, D. L., \& Difiglio, C. (2000). Energy efficiency and consumption-the rebound effect-a survey. Energy Policy, 28(6-7), 389-401.

Hardeman, W., Johnston, M., Johnston, D., Bonetti, D., Wareham, N., \& Kinmonth, A. L. (2002). Application of the Theory of Planned Behaviour in Behaviour Change Interventions: A Systematic Review. Psychology \& Health, 17(2), 123-158.

Hardeman, W., Sutton, S., Griffin, S., Johnston, M., White, A., Wareham, N. J., \& Kinmonth, A. L. (2005). A causal modelling approach to the development of theory-based behaviour change programmes for trial evaluation. Health Education Research, 20(6), 676-87.

Herring, H., \& Roy, R. (2007). Technological innovation, energy efficient design and the rebound effect. Technovation, 27(4), 194-203.

Horvath, I. (2004). A treatise on order in engineering design research. Research in Engineering Design, 15(3), 155-181.

Jackson, T. (2005). Live Better by Consuming Less?: Is There a "Double Dividend" in Sustainable 
Consumption? Journal of Industrial Ecology, 9(1-2), 19-36.

Jordan, E., Gross, M. E., \& Javernick-Will, A. N. (2011). Use and misuse of qualitative comparative analysis. Construction Management and Economics, 29(11), 1159-1173.

Kahneman, D. (2011). Thinking, fast and slow. Farrar, Straus and Giroux.

Kay, A. C., Wheeler, S. C., Bargh, J. A., \& Ross, L. (2004). Material priming: The influence of mundane physical objects on situational construal and competitive behavioral choice. Organizational Behavior and Human Decision Processes, 95(1), 83-96.

Kelders, S. M., Kok, R. N., Ossebaard, H. C., \& Van Gemert-Pijnen, J. E. W. C. (2012). Persuasive system design does matter: a systematic review of adherence to web-based interventions. Journal of Medical Internet Research, 14(6), e152.

Kim, J., Yoon, C., \& Gonzalez, R. (2012). Product expression and self-construal: downstream effects of connected shapes on social connectedness. In Design 2012. Dubrovnik, Croatia.

Kirk, R. E. (2009). Experimental design. London, UK: Sage Publications.

Lehman, P. K., \& Geller, E. S. (2004). Behaviour analysis and environmental protection: Accomplishments and potential for more. Behaviour and Social Issues, 13, 13-32.

Li, I., Dey, A., \& Forlizzi, J. (2010). A stage-based model of personal informatics systems. In Proceedings of the SIGCHI Conference on Human Factors in Computing Systems (pp. 557566).

Lilley, D. (2009). Design for sustainable behaviour: strategies and perceptions. Design Studies, 30(6), 704-720.

Lilley, D., \& Wilson, G. (2013). Integrating ethics into design for sustainable behaviour. Journal of Design Research, 11(3), 278-299.

Lockton, D. (2016). Design with intent. http://designwithintent.co.uk/.

Lockton, D., Harrison, D., \& Stanton, N. (2008). Making the user more efficient: Design for sustainable behaviour. International Journal of Sustainable Engineering, 1(1), 3-8.

Loewenstein, G. F., Weber, E. U., Hsee, C. K., \& Welch, N. (2001). Risk as feelings. Psychological Bulletin, 127(2), 267-286.

Markus, H. R., \& Kitayama, S. (1991). Culture and the Self : Implications for Cognition, Emotion, and Motivation. Psychological Review, 98(2), 224-253.

Marteau, T. M., Ogilvie, D., Roland, M., Suhrcke, M., \& Kelly, M. P. (2011). Judging nudging: can nudging improve population health? Bmj, 342(228).

Michie, S., Johnston, M., Francis, J., Hardeman, W., \& Eccles, M. (2008). From Theory to Intervention: Mapping Theoretically Derived Behavioural Determinants to Behaviour Change Techniques. Applied Psychology, 57(4), 660-680.

Miltenberger, R. (2011). Behavior modification: Principles and procedures. Belmont, CA, USA: Wadsworth Publishing.

Nurkka, P., Kujala, S., \& Kemppainen, K. (2009). Capturing users' perceptions of valuable experience and meaning. Journal of Engineering Design, 20(5), 449-465.

Oinas-kukkonen, H., \& Harjumaa, M. (2008). A Systematic Framework for Designing and Evaluating Persuasive Systems. In Persuasive Technology. Third International Conference, PERSUASIVE 2008 (pp. 164-176).

Ouellette, J. A., \& Wood, W. (1998). Habit and intention in everyday life: The multiple processes by which past behavior predicts future behavior. Psychological Bulletin; Psychological Bulletin, 124(1), 54. 
Prochaska, J. O., Norcross, J. C., \& DiClemente, C. C. (1995). Changing for good. New York: William Morrow \& Co.

Prochaska, J. O., \& Velicer, W. F. (1997). The Transtheoretical Model of Health Behavior Change. American Journal of Health Promotion, 12(1), 38-48.

Rihoux, B. (2006). Qualitative Comparative Analysis (QCA) and Related Systematic Comparative Methods Recent Advances and Remaining Challenges for Social Science Research. International Sociology, 21(5), 679-706.

Rihoux, B., \& Lobe, B. (2009). The case for qualitative comparative analysis (QCA): Adding leverage for thick cross-case comparison. In The Sage handbook of case-based methods (pp. 222-241). Sage.

Rihoux, B., \& Ragin, C. (2009). Configurational comparative methods: Qualitative comparative analysis (QCA) and related techniques. SAGE.

Rihoux, B., Thiem, A., Rubinson, C., \& Defacqz, S. (2016). Compasss software. http://www.compasss.org/software.htm.

Robson, C. (2002). Real world research (Vol. 2nd). Chichester: Wiley.

Roediger, H. L. (1990). Implicit memory. Retention without remembering. The American Psychologist, 45(9), 1043-1056.

Sanders, E. B. N., \& Stappers, P. J. (2014). Probes, toolkits and prototypes: three approaches to making in codesigning. CoDesign, 10(1), 5-14.

Schacter, D. L. (1992). Priming and Multiple Memory Systems: Perceptual Mechanisms of Implicit Memory. Journal of Cognitive Neuroscience, 4(3), 244-256.

Schultz, P. W., Oskamp, S., \& Mainieri, T. (1995). Who Recycles and When? A Review of Personal and Situational Factors. Journal of Environmental Psychology, 15, 105-121.

Selvefors, A., Pedersen, K. B., \& Rahe, U. (2011). Design for sustainable consumption behavior: systematizing the use of behavioral intervention strategies. In Proceedings of the 2011 Conferenceon Designing Pleasurable Products and Interfaces (pp. 242-249). Milan, Italy.

Stapel, D., \& Koomen, W. (2001). I, we, and the effects of others on me: How self-construal level moderates social comparison effects. Journal of Personality and Social Psychology, 80(5), 766-781.

Steg, L., \& Vlek, C. (2009). Encouraging pro-environmental behaviour: An integrative review and research agenda. Journal of Environmental Psychology, 29(3), 309-317.

Sunstein, C. R. (1996). Social norms and social roles. Columbia Law Review, 96(4), 903-968.

Tang, T., \& Bhamra, T. (2008). Changing energy consumption behaviour through sustainable product design. In Design 2008 (pp. 1359-1366). Dubrovnik, Croatia.

Thaler, R. H., \& Sunstein, C. R. (2008). Nudge: Improving decisions about health, wealth, and happiness. London: Penguin.

Tromp, N. (2013). Social Design: How products and services can help us act in ways that benefit society. TU Delft.

Tromp, N., \& Hekkert, P. (2016). Assessing methods for effect-driven design: Evaluation of a social design method. Design Studies, 43(March), 24-47.

Tromp, N., Hekkert, P., \& Verbeek, P. P. (2011). Design for socially responsible behavior: a classification of influence based on intended user experience. Design Issues, 27(3), 3-19.

Ulrich, K. T., \& Eppinger, S. D. (2003). Product design and development (Vol. 5th). New York, USA: MvGraw-Hill. 
Villa, C., \& Labayrade, R. (2014). Solving complex design problems through multiobjective optimisation taking into account judgements of users. Research in Engineering Design, 25(3), 223-239.

Visser, T., Vastenburg, M. H., \& Keyson, D. V. (2011). Designing to support social connectedness: The case of SnowGlobe. International Journal of Design, 5(3), 129-142.

Walker, I. (2010). Research methods and statistics. New York, USA: Palgrave Macmillan.

Wendel, S. (2013). Designing for behavior change: Applying psychology and behavioral economics. O’Reilly.

Williams, L. E., \& Bargh, J. A. (2008). Experiencing physical warmth promotes interpersonal warmth. Science (New York, N.Y.), 322(5901), 606-607.

Wood, G., \& Newborough, M. (2003). Dynamic energy-consumption indicators for domestic appliances: environment, behaviour and design. Energy and Buildings, 35(8), 821-841.

Wynn, D., \& Clarkson, J. (2005). Models of designing. In Design process improvement (pp. 3459).

Zhang, Y., Feick, L., \& Price, L. J. (2006). The impact of self-construal on aesthetic preference for angular versus rounded shapes. Personality \& Social Psychology Bulletin, 32(6), 794805. 